\title{
Blunt trauma - related isolated pancreatic injury
}

\author{
Onder $\mathrm{A}^{1}$, Kapan $\mathrm{M}^{1}$, Tekbas $\mathrm{G}^{2}$, Arikanoglu $\mathrm{Z}^{1}$, Aliosmanoglu $\mathrm{I}^{1}$, Taskesen $\mathrm{F}^{1}$, Girgin $\mathrm{S}^{1}$ \\ Department of General Surgery, Dicle University Faculty of Medicine, Diyarbakir, Turkey. \\ draonder@gmail.com
}

\begin{abstract}
Background: Pancreatic injuries arising from blunt trauma are rarely seen. Diagnosis and treatment are difficult because of retroperitoneal localization of the organ. We present four pancreatic cases with isolated pancreatic injury due to blunt abdominal trauma.

Methods: This retrospective study included four pancreatic patients who were operated on due to isolated injury caused by blunt abdominal trauma at our department between January 2004 and October 2010.

Results: The patients consisted of three males and one female. One of them was in stage IV and the rest were in stage III. All underwent pancreaticojejunostomy, distal pancreatectomy, distal pancreatectomy + splenectomy and drainage, respectively. Fistula developed in two of them, and abscess developed in one, while the other one died. Conclusion: Diagnosis may be delayed since the clinical condition is initially stable. Tomography remains one of the most important diagnostic tools. Common risk factors for morbidity and mortality are the presence of ductal injury and delayed laparotomy (Tab. 1, Fig. 4, Ref. 22). Full Text in PDF www.elis.sk.

Key words: blunt abdominal trauma, isolated pancreatic injury.
\end{abstract}

Current increase in traffic and occupational accidents has caused significant escalation in abdominal traumas. In blunt traumas, pancreas is rarely injured due to its anatomical localization, when compared to solid organs (1). However, pancreas is bound to get injured when remained between the striking power and columna vertebralis even in minor abdominal traumas including fisting, kicking, falls from height or from bike $(2,3)$. While injuries of spleen, liver and kidney reveal immediate departmental findings after the trauma, pancreatic injuries take longer time to reveal any finding, causing morbidity and mortality $(1,2)$. We present four pancreatic cases were isolated pancreatic injury caused by blunt abdominal trauma was evident.

\section{Materials and methods}

This retrospective study included four pancreatic patients who were operated on due to isolated injury caused by blunt abdominal trauma at our department between January 2004 and October 2010. The cases were graded according to 'The Pancreatic Injury Scale' by 'The American Association for the Surgery of Trauma' (4). The patients were analyzed in terms of their age, gender, injury type, duration from injury to operation, preoperational diagnostic methods, grade of injury, injury severity score (ISS), surgical methods performed, length of hospital stay, morbidity and mortality. Patients who had associated organ injuries were excluded. Hemogram, biochemical parameters, PA chest X-ray and serum

${ }^{1}$ Department of General Surgery, Dicle University Faculty of Medicine, Diyarbakir, Turkey, and ${ }^{2}$ Department of Radiology, Dicle University Faculty of Medicine, Diyarbakir, Turkey

Address for correspondence: A. Onder, Department of General Surgery, Dicle University Faculty of Medicine, 21280, Diyarbakir, Turkey.

Phone: +90.412 .2488001 , Fax: +90.412 .2488523$ amylase levels were assessed. Also abdominal ultrasonography (USG) and computed tomography (CT) were obtained. USG and $\mathrm{CT}$ were departmentally and radiologically repeated in patients with possible organ injury, within 48 hours. Operational decision was taken depending on peritonitis findings and/or CT results. During the post-operational period, all patients received adequate fluid replacement, total parenteral nutrition and somatostatin. Postoperational drainages which exceeded $100 \mathrm{mg}$ /day or lasted more than 10 days were accepted as pancreatic fistula (5).

\section{Results}

\section{Patient characteristics}

There were four pancreatic patients in our department, who were operated on due to isolated injury caused by blunt abdominal trauma. Of these, 3 were male and 1 was female. Mean age was as $19.8 \pm 5.7$ (16-28) years. The injuries included traffic accidents (2), fall from height (1), strike (1). One case was in stage IV, while three were in stage III (Tab. 1). Mean ISS was calculated as $10.7 \pm 3.5(9-16)$.

\section{Admission, Operation Periods and Departmental view}

The patients were hemodynamically stable at admission. Mean duration from injury to operation was $7 \pm 11.4(0.5-24)$ hours. For the first patient admitted to our hospital 8 hours after the trauma were evaluated in another institution approximately half an hour after the trauma. The second patient was admitted to our emergency department three hours after the traffic accident. The third patient was operated just 0.5 hour after the trauma in another institution at the 24th hour of follow up. He was transferred to our department for postoperative follow-up and treatment. The fourth patient arrived at our emergency department 24 hours after the trauma. 
Tab. 1. Demographic and clinical characteristics of patients with isolated pancreatic injury.

\begin{tabular}{|c|c|c|c|c|c|c|c|c|c|c|c|c|c|c|}
\hline \begin{tabular}{|c|} 
Case \\
no
\end{tabular} & Age & Gender & $\begin{array}{c}\text { Mechanism } \\
\text { of injury }\end{array}$ & \begin{tabular}{|c|}
$\begin{array}{c}\text { Operation } \\
\text { period } \\
\text { (hour) }\end{array}$ \\
\end{tabular} & $\begin{array}{c}\text { High } \\
\text { amylase } \\
\text { (hour) }\end{array}$ & $\begin{array}{c}\text { WBC } \\
\left(\mathrm{mm}^{3} / \mathrm{dl}\right)\end{array}$ & \begin{tabular}{|c|} 
Acute \\
abdomen \\
(hour)
\end{tabular} & $\begin{array}{c}\text { Ultrasound } \\
\text { findings }\end{array}$ & CT findings & Grade & $\begin{array}{l}\text { Surgical } \\
\text { procedure }\end{array}$ & $\begin{array}{l}\text { Length of } \\
\text { hospital } \\
\text { stay (day) }\end{array}$ & Morbidity & Outcome \\
\hline 1 & 16 & Male & $\begin{array}{c}\text { Falls from } \\
\text { height }\end{array}$ & 0.5 & 8 & 14.700 & 36 & Free fluid & Ductal injury & 4 & $\begin{array}{l}\text { Pancreatico- } \\
\text { jejunostomy }\end{array}$ & 21 & Fistula & Alive \\
\hline 2 & 16 & Male & $\begin{array}{c}\text { Traffic } \\
\text { accident }\end{array}$ & 3 & Normal & 19.500 & 6 & Free fluid & Ductal injury & 3 & $\begin{array}{c}\text { Distal } \\
\text { pancreatectomy }\end{array}$ & 15 & Abscess & Alive \\
\hline 3 & 28 & Male & $\begin{array}{c}\text { Traffic } \\
\text { accident }\end{array}$ & 0.5 & 24 & 15.300 & 24 & Free fluid & Ductal injury & 3 & Drainage & 44 & \begin{tabular}{|c|} 
Fistula \\
+ abscess
\end{tabular} & Death \\
\hline 4 & 19 & Female & Assault & 24 & 24 & 15.000 & 24 & Free fluid & Ductal injury & 3 & $\begin{array}{c}\text { Distal } \\
\text { pancreatectomy } \\
+ \text { splenectomy }\end{array}$ & 10 & None & Alive \\
\hline
\end{tabular}

USG - Ultrasound, CT - Computed Tomography, WBC - White blood cells

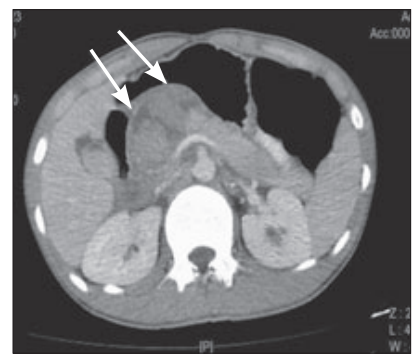

Fig. 1. Axial post-contrast CT images: hypodense laceration tract and mild hypodense hematoma in head and neck of pancreas.

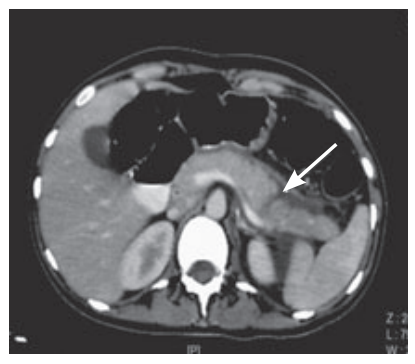

Fig. 2. Axial post-contrast CT images; laceration at the corpus-caudal junction.

The mean interval between trauma and operation was revealed as $22.5 \pm 12.4$ (6-36) hours. Free fluid was detected on ultrasound in the first patient on the day he was hospitalized at our department. The suspected lesion detected in the pancreas by CT on the first day was considered to be hematoma. On the second day, ductal injury was detected at the junction between head and corpus on CT (Fig. 1). The patient was operated on at the 36th hour. As with the second case, free abdominal fluid was detected by ultrasound, and ductal injury was detected in distal pancreas on CT. He was operated on at the 6 th hour as peritonitis signs emerged. The third case was operated on due to acute abdomen signs after a 24-hourfollow-up in another institution. The fourth patient was admitted to our emergency department 24 hours after the strike. She did not have a traumatic anamnesis. Free fluid was detected on the ultrasound, while amylase level was high. Hemorrhagic fluid was obtained through paracentesis. Upon the high amylase level measured from the fluid, she professed the truth, stating that she had had an abdominal strike 24 hours before. Afterwards, she was operated on due to a ductal injury detected at the corpus-caudal junction (Fig. 2).

\section{Serum amylase level}

Preoperative serum amylase levels were studied. The value for the first patient was normal in the other institution, while it was slightly high (147 U/L) during the 8th hour after he had arrived to our department, and it gradually raised thereafter (611-724-955-1517 $\mathrm{U} / \mathrm{L}$ ). The amylase level for the second patient was initially normal.

However, he was operated on at the 6th hour as a result of peritonitis and CT results. The third patient had a level of $1055 \mathrm{U} / \mathrm{L}$ while the level for the fourth patient was too high to assess at 24th hour.

\section{Imaging methods}

Ultrasound and CT were undertaken in all the patients. Free abdominal fluid was detected on ultrasound, and ductal injury on CT. Ultrasound and CT were repeated for the first and the fourth patient till their surgical intervention.

\section{Surgical procedure}

The first patient presented with pancreatic transect and hematoma near the pancreas head. Hematoma was drained. Proximal duct was ligatured following debridement (Fig. 3). Pancreaticojejunostomy was applied to the distal part as Roux-en-Y. The second and third patients underwent distal pancreatectomy as the ductal injury was in distal pancreas (Fig. 4). The third patient also received splenectomy since distal pancreatectomy and the spleen could not be saved. As for the fourth patient, primary suturing and hemostasis were applied because ductal injury was overlooked in the other institution. Drainage was applied twice in the follow-up due to fistula and abscess development.

\section{Postoperative period}

Mean length of hospital stay was $22.5 \pm 15.0$ (10-44) days. Ultrasound-guided percutaneous drainage was performed for the peripancreatic abscess with the second patient. Fistula developed in the first and the third patients. In the first patient, fistulous flow rate was $150 \mathrm{cc}$ per day, which was closed spontaneously 21 days later. The third patient had a flow rate of $>500 \mathrm{cc}$ after the initial operation. Laparotomy was performed on the postoperative day 13 as the flow rate did not reduce, and the patient had continuous fever while abscess formation was detected in peripancreatic and pelvic regions on Ultrasound and CT. Pancreatic region could hardly be explored and drained due to intense abscess and fibrotic tissue. A second drainage was performed on the postoperative day 20 because of repeated abscess formations. Mortality occurred in the fourth patient as a result of sepsis caused by abscess and fistula formations and due to multi-organ failure, on the 44th day of the first operation. With the remaining three patients, no exocrine or endocrine failure was detected during the 1 st and 3rd monthly checks. 


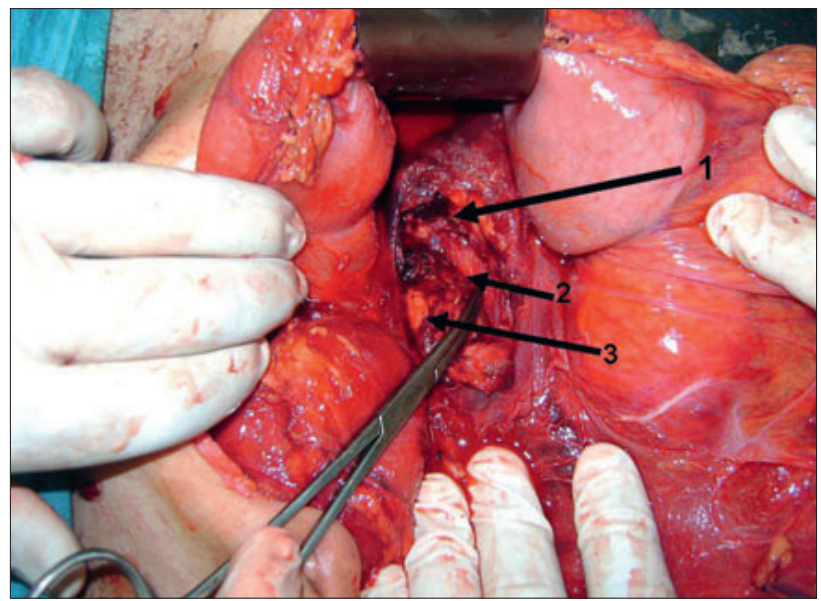

Fig. 3. Intraoperative view of the first patient after drainage and debridement. First arrow shows distal pancreas, second arrow shows vena mesenterica superior, and third arrow shows pancreatic head.

\section{Discussion}

Approximately $1 / 3$ of pancreatic injuries consist of blunt injuries, which constitutes $0.2 \%$ of blunt abdominal traumas. Isolated pancreatic injuries are relatively rarer and they are reported to represent $3-10 \%$ of pancreatic injuries $(6,7)$. Pancreatic injuries are reportedly more frequent among young adults due to the scarcity of the protective fat tissue which functions as a cushion in retroperitoneal region $(8,9)$. A total of 443 subjects with blunt abdominal trauma were admitted to our emergency department between January 2004 and October 2010. Among these, isolated pancreatic injuries represented $0.9 \%$. Since pancreatic injuries are commonly accompanied by injuries in the stomach, vascular structure and liver, the findings of other organ injuries become prominent and thus pancreatic injury is only diagnosed during laparotomy. As with the isolated pancreatic injuries, the retroperitoneal localization of the organ causes delayed symptoms and findings, causing a difficulty with diagnosis $(7,10)$.

The serum amylase levels are reported normal in $25 \%$ of the patients presenting with pancreatic injury (7). However, Akcan et al (5) report that the serum amylase levels at admission are high in $73 \%$ of the patients and that this rate increases to $89 \%$ after serial measurements. Moreover, the amylase level measured within the first 3 hours following the trauma does not have a diagnostic significance, on the other hand it is found to be more significant thereafter $(11,12,13)$. A correlation was not found between ductal injury and serum amylase level (14). In this study, the amylase levels were normal in two patients at admission. Initial physical examination findings were nonspecific in our patients, yet peritonitis findings emerged thereafter. In light of these data, the patients with pancreatic injuries should be followed up. We consider the amylase as a method which is not diagnostic or exclusionary in pancreatic injuries but which could play an important role in the diagnosis of pancreatic injuries together with the findings and images of physical examination since its sensitivity increases gradually.

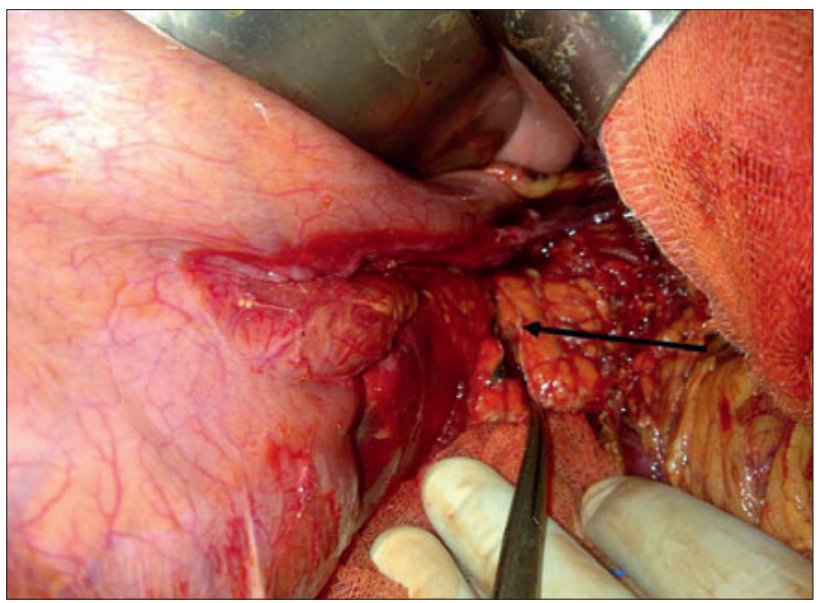

Fig. 4. Intraoperative view of the third patient with distal pancreatic injury. The arrow shows ductal injury.

Ultrasound remains the primary option in the diagnosis of abdominal traumas. Being performed bedside and providing information about the presence of intraabdominal free fluid and about the accompanying organ injuries are among its important advantages. Yet, Ultrasound is not very useful in diagnosis due to the retroperitoneal location of the organ (15). CT is not only useful in proper evaluation of the pancreas and other solid organs of hemodynamically stable patients but is also an important imaging method in operational decision-making. CT is known to visualize ductal pancreas injuries at a rate of $68-100 \%(15,16)$. The findings on CT which may indicate pancreatic injury are: a) intra- and extraperitoneal fluid, fluid in the lesser sac; b) pancreatic hematoma or laceration; c) diffuse gland enlargement with pancreatitis or focal edema at the site of the injury; d) thickening of the left anterior renal fascia (17). These findings are unusual and often subtle and patients with pancreatic injury rarely exhibit more than one finding. The success rate of CT that is repeated after 24 hours is reportedly higher due to fluid accumulation and edema development around the pancreas (18). While only intraabdominal free fluid was detected on USG in all patients, ductal injury was detected on CT. In abdominal injuries arising from blunt trauma, CT on the thin sections obtained from the patient may increase the possibility of early diagnosis and reduce the risk of overlooking pancreatic injuries.

The most important factor that determines the operational strategy and affects mortality and morbidity is pancreatic duct injury $(10,15,17,19)$. If the injury does not include ductal injury (Grade I-II), primary suturing and drainage are performed; if ductal injury is on the left of vena mesenteric superior (VMS) (Grade III), distal pancreatectomy is recommended. In this case spleen may be protected at a rate of $44 \%$. If injury is on the right of VMS (Grade IV) and more than $90 \%$ resection is required, pancreaticojejunostomy is performed in order to prevent endocrine and exocrine pancreatic failure; and in injuries located at the pancreatic head, damage control surgery or pancreaticoduodenectomy is performed $(1,17,19,20)$. In our study, all the patients presented with ductal injury. In two of them, distal pancreatectomy was undertaken as pancreas was transected on the left to VMS. 
One of them also underwent splenectomy as it was not possible to preserve the spleen. The patient who was traumatized on the right of VMS received pancreaticojejunostomy. Fistula developed in the last patient since ductal injury had been overlooked during the operation in another institution. In subsequent laparotomies, only drainage was performed since definite surgery could not be performed because of intense abscess and fibrosis.

Somatostatin and its analogue, octreotide, are reported to reduce the flow rate of pancreatic fistula in retrospective studies (16, 21). All of our patients received somatostatin infusion during the postoperative 7 days. However, fistula development could not be prevented in two cases. It is not suitable to comment on this phenomenon because the series of our subjects was too small.

The complications caused by pancreatic injury including fistula, abscess, pancreatitis, anastomosis leakage, pseudocyst, exocrine and endocrine failure are observed at a rate of 35-64\% (20). Fistula is the most common complication in pancreatic injuries and it frequently develops in injuries near pancreatic head. Ninety percent of them are spontaneously closed in a period ranging between 2 weeks and 2 months (17).

Mortality rate in pancreatic injuries is reported to be 16-24\% (22). Early deaths are related to vascular hemorrhage, whereas late deaths are generally caused by the sepsis arising from ductal injury or by multi-organ failure (19). In the first patient, postoperative fistula developed as the injury was near the pancreatic head, which was spontaneously closed 3 weeks later. In another patient, the peripancreatic abscess was drained. No exocrine or endocrine failure was observed in any of our patients. In the last patient, who ended up with mortality, fistula developed because ductal injury was overlooked in the first operation and because appropriate surgical procedures could not be performed. He died due to fistula-induced sepsis and multi-organ failure.

Limitation of this study include lower number of cases and its retrospective study design. It will be helpful to design this study as prospectively in larger series to understand the relation of the departmental approach in pancreatic injury with morbidity and mortality.

\section{Conclusion}

Diagnosis may be delayed since the clinical condition is initially stable. The most important strategy to prevent diagnostic delay is suspecting. CT plays a major role in detecting ductal injury. Common risk factors for morbidity and mortality are the presence of ductal injury and delayed laparotomy. For the cases suspected with pancreatic injury, an immense effort should be exerted to diagnose ductal injury, and immediate intervention should be performed if needed.

\section{References}

1. Karabulut Z, Bostanoglu S, Besim H, Hamamci O, Korkmaz A. Pancreatic Injuries: Analysis of 20 cases. Turk J Trauma Emergency Surg 2002; 13: 300-306.

2. Oncel M, Dalkilic G, Yildiz H, Sagiroglu T, Gezen C, Olcay E. Minör trauma Major injury with isolated pancreatic trauma "case report". Turk J Trauma Emergency Surg 1998; 4: 289-291.
3. Fleming WR, Collier NA, Bouting SW. Pancreatic trauma: Universities of Melbourne HPB group. Aust NZ J Surg 1999; 69: 357-362.

4. Moore EE, Cogbill TH, Malangoni MA et al. Organ injury scaling. Surg Clin North Am 1995; 75: 293-303.

5. Akcan A, Akyildiz H, Kucuk $C$ et al. Surgical approach to pancreas injury: A 15 years experience. Turk J Surg 2006; 3: 104-108.

6. Young PR Jr, Meredith JW, Baker CC, Thomason MH, Chang MC. Pancreatic injuries resulting from penetrating trauma: a multi-institution review. Am Surg 1998; 64: 838-843.

7. Ahmad I, Branicki FJ, Ramadhan K, El-ashaal Y,Abu-Zidan FM. Pancreatic injuries in the united arab emirates. Scand J Surg 2008; 97: 243-247.

8. Beckingham IJ, Krige JE. ABC of diseases of liver, pancreas, and biliary system: Liver and pancreatic trauma. BMJ 2001; 322: 783-785.

9. Kantarci F, Gürses B, Albayrak R, Aksoy S.H, Kurugoglu S, Mihmanli I. An isolated complete pancreatic fracture primarily diagnosed by ultrasound. Turk J Trauma Emergency Surg 2004; 10: 138-140.

10. Govaert MJ, Ponsen KJ, de-Jonge L, de-Wit LT, Obertop H. Fracture of the pancreas in two patients after a go-kart accident. HPB 2001; 3: 3-6.

11. Hata M, Murao Y, Konobu T, Okuchi K, Nakajima Y. Laparoscopic treatment for peripheral pancreatic duct injury after blunt abdominal trauma: report of a case. Surg Today 2002; 32: 659-662.

12. Bradley EL, Young PR, Chang MC et al. Diagnosis and initial management of blunt pancreatic trauma. Ann Surg 1998; 227: 861-869.

13. Takishima T, Sugimoto K, Hirata $M$ et al. Serum amylase level on admission in the diagnosis of blunt injury to the pancreas. Ann Surg 1997; 226: 70-76.

14. Tan KK, Chan DX, Vijayan A, Chiu MT. Management of Pancreatic Injuries after Blunt Abdominal Trauma. Experience at a Single Institution. J Pancreas 2009; 10: 657-663.

15. Ilahi O, Bochicchio GV, Scalea TM. Efficacy of computed tomography in the diagnosis of pancreatic injury in adult blunt trauma patients: a single-institutional study. Am Surg 2002; 68: 704-708.

16. Lochan R, Sen G, Barrett AM, Scott J, Charnley RM. Management strategies in isolated pancreatic trauma. J Hepatobiliary Pancreat Surg 2009; 16: 189-196.

17. Bedirli A, Sakrak O, Sozuer EM, Guler I, Aritas Y. Surgical alternatives in complex pancreatic injuries. Turk J Trauma Emergency Surg 2003; 9: 194-198.

18. Holland AJ, Davey RB, Sparen AL, Chapman M, LeQuesne GW. Traumatic pancreatitis: long term review of initial non-operative management in children. J Pediatric Child Health 1999; 35: 78-82.

19. Caglayan K, Koksal N, Onur E et al. Our eight years' departmental experience in pancreatic injuries. Turk J Trauma Emergency Surg 2007; 13: $300-306$.

20. Olah A, Issekutz A, Haulik L, Makay R. Pancreatic transection from blunt abdominal trauma: early versus delayed diagnosis and surgical management. Dig Surg 2003; 20: 408-414.

21. Boffard KD, Brooks AJ. Pancreatic Trauma - Injuries to the Pancreas and Pancreatic Duct. Eur J Surg 2000; 166: 4-12.

22. Canty TG Sr, Weinman D. Management of major pancreatic duct injuries in children. J Trauma 2001; 50: 1001-1007.

Received August 29, 2011. Accepted January 30, 2013. 